\title{
Erratum to: Safety and Efficacy of a Circumferential Clip-Based Vascular Closure Device in Cirrhotic and Coagulopathic Patients with Hepatocellular Carcinoma After Doxorubicin Drug-eluting Beads Transarterial Chemoembolization
}

\author{
Hasmukh J. Prajapati · Shoaib Rafi • \\ Faramarz Edalat · David A. Kooby • \\ Hyun S. Kim
}

Published online: 24 August 2013

(C) Springer Science+Business Media New York and the Cardiovascular and Interventional Radiological Society of Europe (CIRSE) 2013

Erratum to: Cardiovasc Intervent Radiol

DOI 10.1007/s00270-013-0709-9

The article was published with an incorrect corresponding author. The correct corresponding author is Hyun S. Kim, as shown in this erratum.

The online version of the original article can be found under doi:10.1007/s00270-013-0709-9.

H. J. Prajapati · S. Rafi · F. Edalat · H. S. Kim $(\bowtie)$ Division of Interventional Radiology and Image-Guided Medicine, Department of Radiology, Winship Cancer Institute, Emory University School of Medicine, 1364 Clifton Road NE, Suite AG-05, Atlanta, GA 30322, USA

e-mail: kevin.kim@emory.edu; HKIM286@emory.edu

H. J. Prajapati

e-mail: hasmukhjpr@hotmail.com

D. A. Kooby $\cdot$ H. S. Kim

Division of Surgical Oncology, Department of Surgery, Winship Cancer Institute, Emory University School of Medicine, Atlanta,

GA 30322, USA 